\title{
Modelling of the Biomass mCHP Unit for Power Peak Shaving in the Local Electrical Grid
}

\author{
Michał Gliński ${ }^{1, *(\mathbb{D})}$, Carsten Bojesen ${ }^{2}$, Witold Rybiński ${ }^{1}$ and Sebastian Bykuć ${ }^{1}$ (i) \\ 1 Distributed Energy Department, The Szewalski Institute of Fluid-Flow Machinery Polish Academy of \\ Sciences, 80-231 Gdańsk, Poland; witold.rybinski@imp.gda.pl (W.R.); sbykuc@imp.gda.pl (S.B.) \\ 2 The Faculty of Engineering and Science Department of Energy Technology Thermal Energy Systems, \\ Aalborg University, 9220 Aalborg, Denmark; cbo@et.aau.dk \\ * Correspondence: mglinski@imp.gda.pl
}

Received: 21 December 2018; Accepted: 29 January 2019; Published: 31 January 2019

\begin{abstract}
In the article, the method and algorithm for a control strategy of the operation of a micro combined heat and power (mCHP) unit and for reducing the power consumption peaks (peak shaving) are proposed and analyzed. Two scenarios of the mCHP's operation, namely with and without the control strategy, are discussed. For calculation purposes, a boiler fired with wood pellets coupled with a Stirling engine, manufactured by ÖkoFEN, was used. These results were used to analyze two scenarios of the control strategy. In this study, the operation of mCHP was simulated using the energyPRO software. The application of this control strategy to dispersed mCHP systems allows for a very effective "peak shaving" in the local power grid. The results of calculation using the new algorithm show that the electricity generated by the mCHP system covers the total demand for power during the morning peak and reduces the evening peak by up to $71 \%$. The application of this method also allows for a better reduction of the load of conventional grids, substations, and other equipment.
\end{abstract}

Keywords: control strategy; peak-shaving; $\mathrm{mCHP}$; Stirling engine; renewable energy; energy consumption profile

\section{Introduction}

Nowadays in Poland, $\approx 80 \%$ of the electricity is generated in the central coal-fired power plants and transmitted through the old electric grids to distant customers [1]. In addition, most households have heating systems based on high emission coal-fired boilers, which have a low efficiency. One of the possibilities to solve these problems is a wide application of modern highly efficient a micro combined heat and power (mCHP) unit powered by renewable energy sources (RES). It could decrease the load of electric grids and reduce air pollution from fossil fuels.

In 2004, the European Directive 2004/8/EC (together with the amendments in 2012/27/EU [2]) was introduced in EU countries to increase energy efficiency and strengthen the power supply security by developing highly efficient combined heat and power production in cogeneration, i.e., CHP plants. An additional aspect is a reduction of the negative impact from the combustion of fossil fuels on the environment and on global warming. Over many years, the European Directives have been limiting the emission of greenhouses gases into the atmosphere. Therefore, in recent years in many countries, one can observe an increase in the share of energy produced using renewable energy sources (RES) and decentralized CHP plants. Nowadays, the main aim is to optimize the generation of heat and electricity as well as reduce the losses due to energy transmission.

The conversion of the production of heat and electricity using fossil fuels to the production using renewable energy sources (RES) has already started and is implemented globally to some 
extent. In some countries, the conversion is well underway and in others it has just started. A large part of the renewable energy sources is characterized as non-controllable and fluctuating. One of the consequences of this is that the energy supply structure will change from the demand-controlled supply to the availability-controlled consumption. Furthermore, conversion to RES should be accompanied by a detailed study of how the discrepancy between availability and consumption can be balanced and how to achieve built-in flexibility.

A sector where there is a potential for flexibility and balancing the energy consumption covers households. This sector also accounts for a major part of the total electricity and heat consumption.

The consumption of electricity is increasing but the local power transmission grid has not been changed and updated properly. Old wires and transmission equipment and their integration with RES power systems have a negative impact on the operational parameters of the power grid such as voltage reduction, frequency fluctuation, etc. Higher consumption of electricity, specifically during daytime, generated huge peaks of power consumption in the grid. These peaks have a huge impact on fluctuations in the grid and can lead to an overload or blackout [3]. That is why in many countries, the demand side management introduces the peak-time tariffs for the reduction of energy consumption in households [4-6]. Globally, morning and evening power peaks in the power grid were distinguished. Therefore, many studies focus on strategies for peak shaving in the electrical grid for better power quality and lower energy transmission losses. In many publications, battery energy storage systems (BESS) and electric vehicles (EVs) applied to peak smoothing were reviewed and analyzed $[7,8]$. However, these technologies are still too expensive for wide residential application.

One type of the considered devices for cogeneration in residential areas are micro combined heat and power (mCHP) systems with electric power production of 1-5 kWe. Such systems have very high overall efficiencies of total energy conversion, which can reach $90 \%[9,10]$. Recently, mCHP units are used mainly for heat production, where electricity is generated as the support of the power grid. The interest in mCHP systems based on renewable energy sources (RES) and their development are growing. Some examples are:

mCHP system with an internal combustion engine (ICE) using methanol as fuel.

$\mathrm{mCHP}$ system with an external combustion engine like a Stirling engine (SE) or an organic Rankine cycle (ORC) system using biomass as fuel.

Fuel cell supplied by hydrogen.

For the purpose of this work, the ÖkoFEN mCHP unit [11] fed with biomass in the form of pellets was chosen for further analyses. It was initially assumed, and then verified, that the heating power of the device together with the appropriate heat storage meets the requirements for the heat supply of the example house described in Section 3 of this work. A higher capacity heat storage extends the possibilities for application of this $\mathrm{mCHP}$ unit for higher heat demand cases. There are also $\mathrm{mCHP}$ devices of higher power on the market; however, most of them are fueled with natural gas. Regardless of their power, they can be used for electricity peak shaving in a similar way as described in this paper.

Most publications concerning mCHP units, energy storages, and load-shifting control strategies are focused on one or two of these topics, but rarely on a combination of all three [12-14]. This article presents $\mathrm{mCHP}$ devices as smart power generation systems where heat and electricity are generated only during periods of high demand for electricity in a household.

This description is intended as an introduction to two articles: about peak shaving and the further about impact on the environment using biomass in distributed mCHPs instead of coal in central power plant during the peaks.

The main purpose of this article is to develop a method and algorithms that can be used for the control strategy of the operation of an $\mathrm{mCHP}$ unit in order to reduce its power consumption peaks (peak shaving). Two scenarios of the $\mathrm{mCHP}^{\prime}$ s operation, namely with and without the control strategy, are presented. The profiles of power and heat demand were created and used to calculate 
the power and heat production of a biomass-fired $\mathrm{mCHP}$ device that operates in an exemplary house. For the calculation purposes, data of a boiler fired with wood pellets coupled with a Stirling engine, manufactured by ÖkoFEN, are used. The data are as follows: a nominal thermal power of $9 \mathrm{kWth}$ and an electrical power of $0.6 \mathrm{kWe}$ at the total efficiency of $90 \%$ (with peaks of $13 \mathrm{kWth}$ and $1 \mathrm{kWe}$ respectively) [11]. These results were used to analyze two scenarios of the control strategy. In the first scenario, the standard control of the mCHP unit, which depended on the water temperature in the heat storage tank, was assumed. In the second scenario, the operation time of the mCHP depends on the duration of morning and evening peaks of energy demand. In this study, the operation of the mCHP unit was simulated using the energyPRO 4.0 software. The application of this control strategy to dispersed mCHP devices allows for a very effective "peak shaving" in the local power grid. The surplus of the heat produced by the domestic mCHP device is stored in a tank and can be used for heating.

\section{Review of the Literature}

Different studies highlighted the advantages of an $\mathrm{mCHP}$ system in a typical residential building [15-17]. Martinez et al. [17] provides a broad review of available micro combined heat and power systems. The first part of this review is focused on the existing energy conversion devices with internal combustion engines (ICEs) and other propulsion systems such as Stirling engines, organic Rankine cycle (ORC) systems, and fuel cells. The second part deals with the mCHP systems supplied by renewable energy sources, mainly the solar energy-based technologies (e.g., PVT combined with an ORC system). Based on this thorough analysis, the cogeneration plant can achieve a total efficiency of $75-95 \%$. They concluded that mCHP systems with ICEs are characterized by a higher efficiency than the other devices, but they also indicated that an mCHP system with a Stirling engine is an attractive technology thanks to external combustion where biomass or waste can be used as fuel.

Rosato et al. [18] analyzed the operational performance of mCHP units coupled with thermal storage tanks situated in several apartment buildings. They both agreed that $\mathrm{mCHP}$ systems are both profitable and reliable and can be more energy-efficient than traditional power systems. The mCHP technologies with microturbines and Stirling engines can provide a proper fit to the demand of each household with regard to a positive ratio between thermal and electrical energy than other solutions like ICEs or fuel cells [19]. They indicated that mCHP systems can play an important role in the household production of electricity, even exceeding the amount produced by a domestic photovoltaic (PV) plant.

Ummenhofer et al. [20] carried out experimental tests of an mCHP unit with an ICE coupled with a thermal energy storage (TES) and an electric energy storage (EES). They focused on the performance of charging and discharging the EES to improve peak time coverage of the power grid. The smart control system of the mCHP device coupled with the EES was applied. They indicated that an appropriate selection of the specific system's components with correct management of the working time of the tested mCHP system gave additional benefits associated with higher coverage during periods of peak energy demands and a shorter run time. In general, the number of run-time cycles of the mCHP unit has a greater impact on the level of self-sufficiency achieved than their respective run-time duration. Both the operation time and start-up time of the mCHP unit with the EES should be adapted to a residential setting and different peak energy demand periods.

In Reference [21], dynamic modelling was conducted to investigate the significant impact of the demand side management (DSM) on the operational performance of air supply heat pumps (ASHPs) with mCHP units for heating a residential building. Cooper et al. [21] show that the DSM can reduce the peak electricity demand of a heat pump in the local power grid. However, in the investigated scenarios, it is unlikely that the peak demands can be reduced sufficiently such that they will not exceed the capacity of the local distribution transformer if ASHPs are used in all dwellings. By using a combination of mCHP units with ASHPs, it is possible to supply heating to all dwellings without exceeding this capacity. The authors concluded that heat pumps with $\mathrm{mCHP}$ units do not achieve the 
maximum performance due to a limitation in the operation regimes of the DSM, which are optimized for the power grid.

Angrisani et al. [22] carried out simulations to assess the thermo-economic performance of an $\mathrm{mCHP}$ system used in households with a low energy demand. They focus on the estimation of the economic profitability of a cogeneration system since it is strongly influenced by the amount of electricity generated and consumed by its user. The results of this study indicate that the installation of mCHP systems in buildings with a low energy demand allows for increasing the percentage of electricity generated and consumed by users. It reduces the bidirectional electricity flow between the users and the power grid, and its impact on the grid due to the large diffusion of distributed generation systems. Moreover, this study shows that the load sharing approach among users with different load profiles leads to better energy and economic results compared to conventional systems. Weather conditions have a strong influence on the operational hours of the mCHP unit, which obviously affects the thermo-economic performance of the system.

\section{Energy Consumption Profile}

For analysis purposes, a typical 250-square-meter house, localized in Legionowo near Warsaw in Poland, was assumed. The house was built using outdated residential building methods, and its energy performance coefficient was equal $110 \mathrm{kWh} / \mathrm{m}^{2}$ year, so the building had a higher heat loss to the atmosphere than new low-energy buildings. The house was inhabited by four people, two adults and two children. For working days in winter, the power consumption daily profile was assumed based on the internal reports of the Institute of Fluid-Flow Machinery, as shown on the plot in Figure 1. For the remaining seasons, the power consumption profiles were determined based on the standard customer's profile from tariff G11 from the Polish energy group ENEA. The following are examples of the power profiles for this house in central Poland.

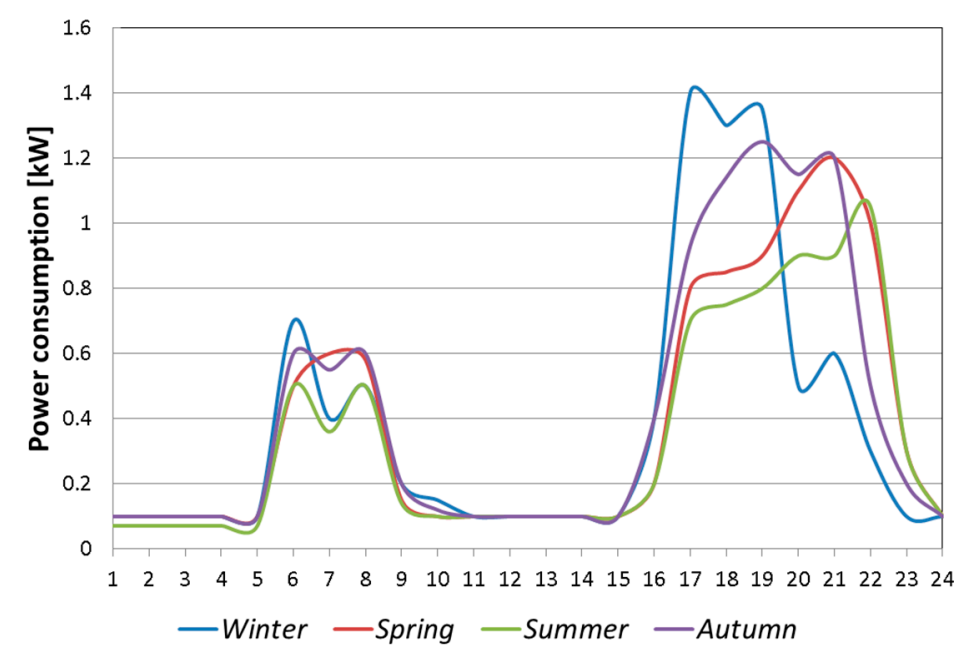

Figure 1. Average power consumption profile of one day.

In Figure 1, two peaks of power consumption are observed. These power peaks are called morning and evening peaks, and occur when the inhabitants are the most active in the house. Yearly demand for electricity in that house was calculated and was $\approx 3.6 \mathrm{MWh}$. The morning peaks occurred at the almost same time; however, the winter one was the highest and the summer one was the lowest. The autumn evening peak was shifted by $2 \mathrm{~h}$ in comparison to the winter one at $5 \mathrm{pm}$, the spring one by $4 \mathrm{~h}$, and the summer one by $5 \mathrm{~h}$. The winter evening peak was also the highest while the summer one was the lowest; however, the differences were higher than in the morning.

The heat demand for space heating was calculated as well. The heat loss of the building was calculated based on the heat transfer coefficient, temperature differences, and heat transfer area of the main construction elements. The heat loss due to the ventilation system was also taken into 
account. However, the radiation effect of the sun was not taken into account. The outdoor temperature measurements in 2015 were obtained (through the energyPRO software) from the meteorological station located in Legionowo near Warsaw. These data were used in an MS Excel 2013 program to calculate the heat demand for heating each hour and exported as a time series to the energyPRO software. The heating season started on 1 October 2015, and ended on 31 May 2015. In Figure 2, the profiles of the outdoor temperature on a representative day of four seasons are presented.

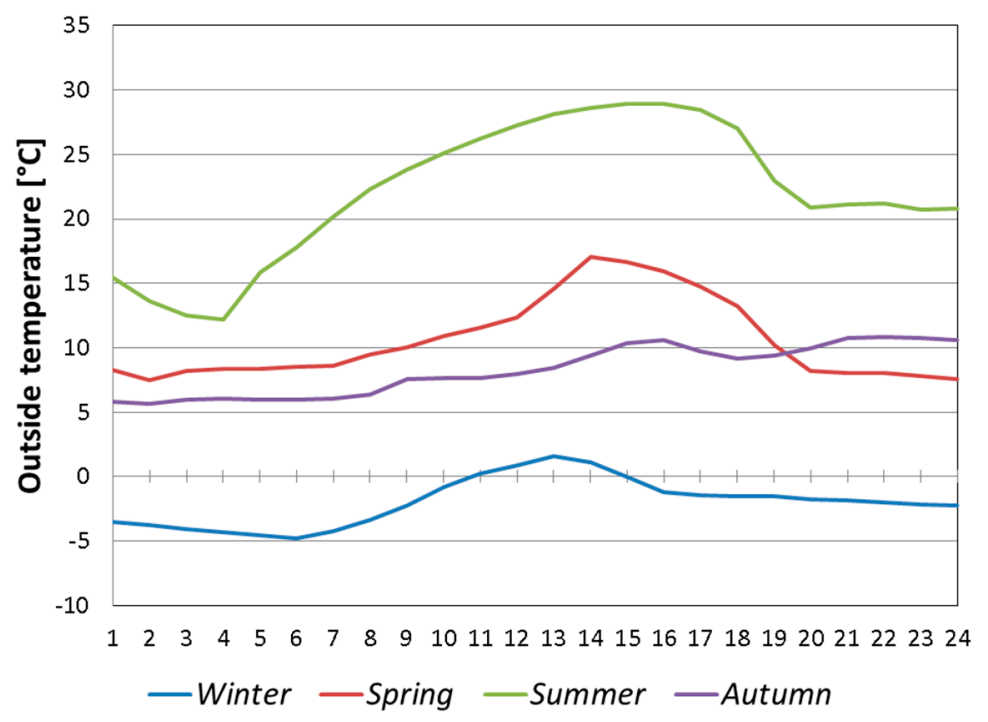

Figure 2. Outside temperature within one day in different seasons.

The temperature inside the building during the heating season was assumed to be $20{ }^{\circ} \mathrm{C}$ when the house was occupied and $16{ }^{\circ} \mathrm{C}$ otherwise. The house was occupied by four persons from $12 \mathrm{a} . \mathrm{m}$. to 8 a.m. and from 4 p.m. to 12 a.m., and not occupied from 8 a.m. to 4 p.m.

Based on the above assumptions, the heat demand was calculated. In Figure 3, the heating profile of space heating is shown. One can notice that the heat demand strongly depended on the outside temperature and on the number of people in the house (the morning and evening peak demands). During the working day with no people inside, the heat consumption was 30-80\% lower than during morning and evening activities.

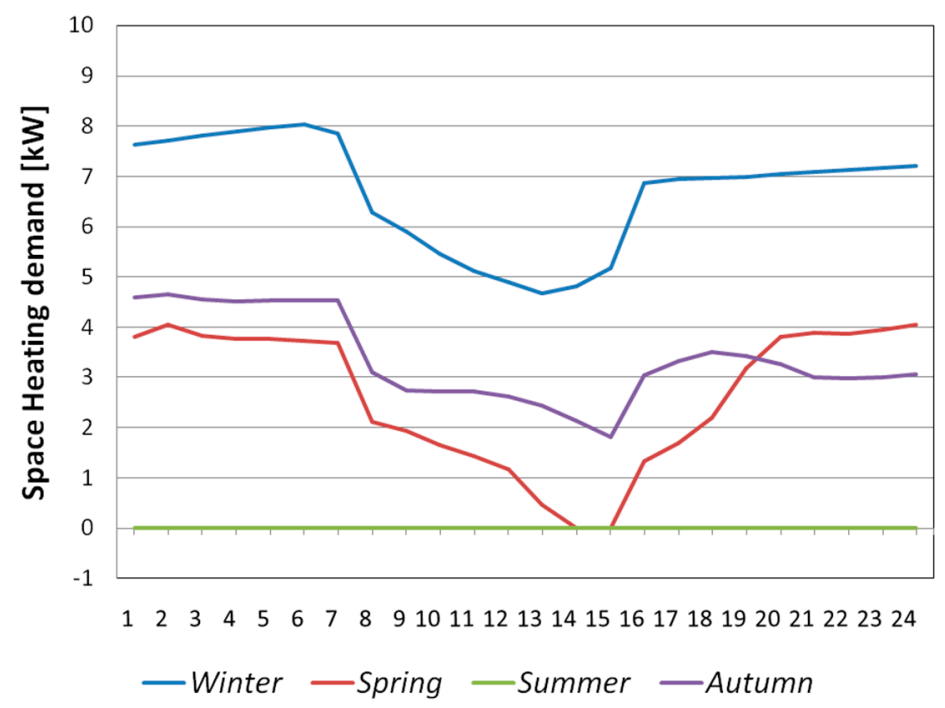

Figure 3. Heat demand for space heating within one day in different seasons. 
Based on the experimental data [23], the heat demand for heating of the domestic hot water (DHW) was assumed. Figure 4 shows the profiles of the heat demand for DHW for each representative day. As can be seen on the plot, morning and evening peak heat demand can also be distinguished.

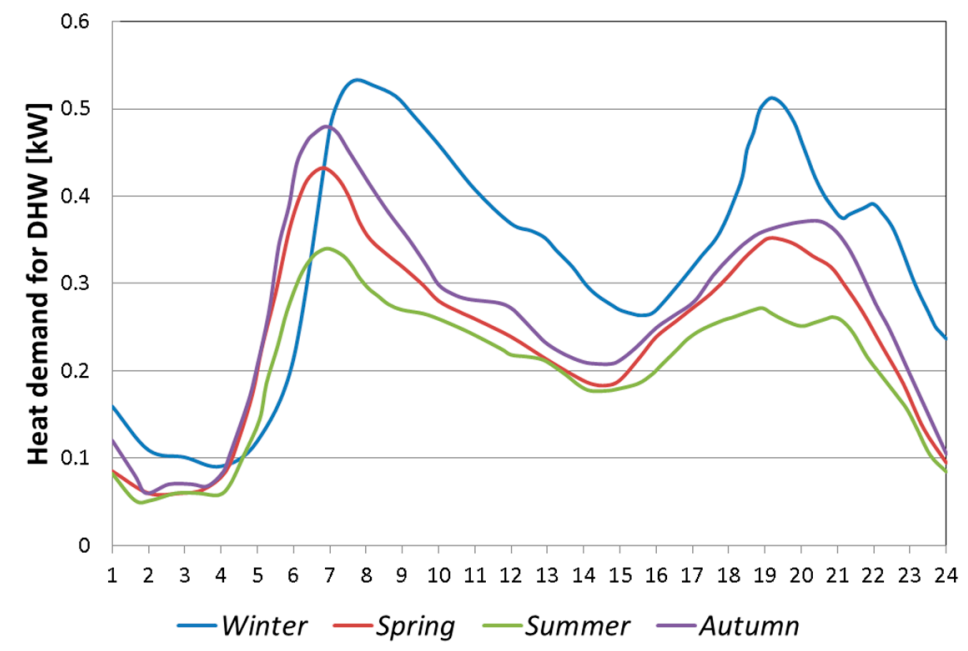

Figure 4. Heat demand for domestic hot water (DHW) within one day in different seasons.

Figure 5 shows the total heat demand (the sum of space heating and DHW heating) for a representative day for each season. The yearly demand for heat was equal $27,654 \mathrm{kWh}$ and for electricity $3600 \mathrm{kWh}$ as calculated using the energyPRO software. In the summer, heat demand was only for heating DHW. The greatest demand for heat took place during winter when the heat was consumed for space heating and DHW. In the transition period (spring or autumn), the heat demand was 2 times lower than during the winter season. Figure 6 presents the comparison of heat and power consumption. Each respective morning and evening peak consumption of the heat and electricity took place at the same time across seasons.

To reduce the amount of electrical energy drawn from the grid during morning and evening peak demands, both heat and electricity should be produced using an mCHP cogeneration system.

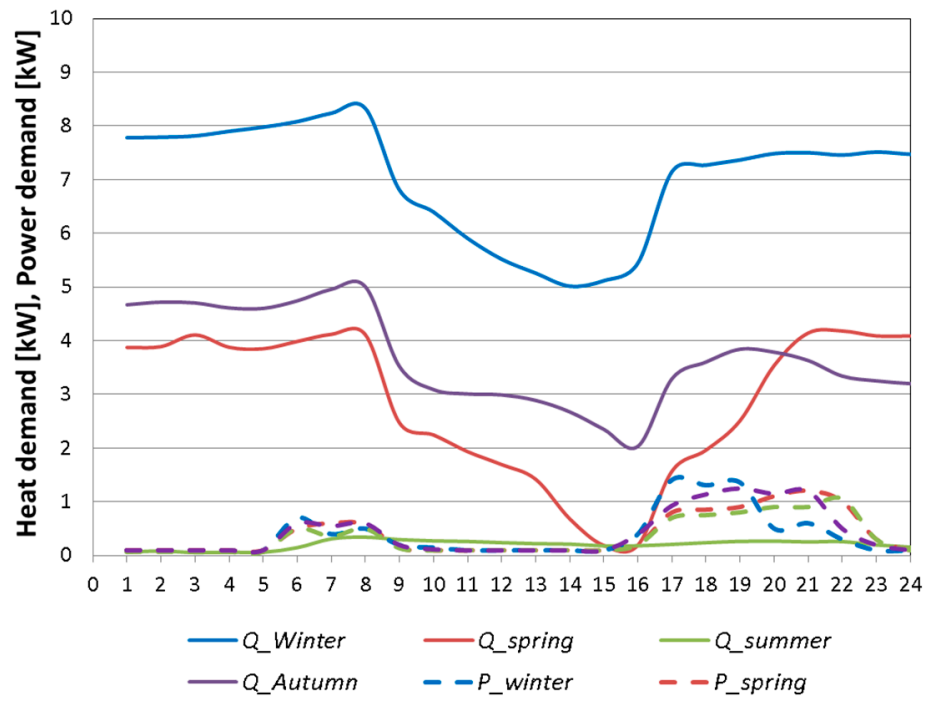

Figure 5. Total heat demand (solid line) for space heating and DHW within one day in different seasons and the assumed power demand profile (dashed line). 


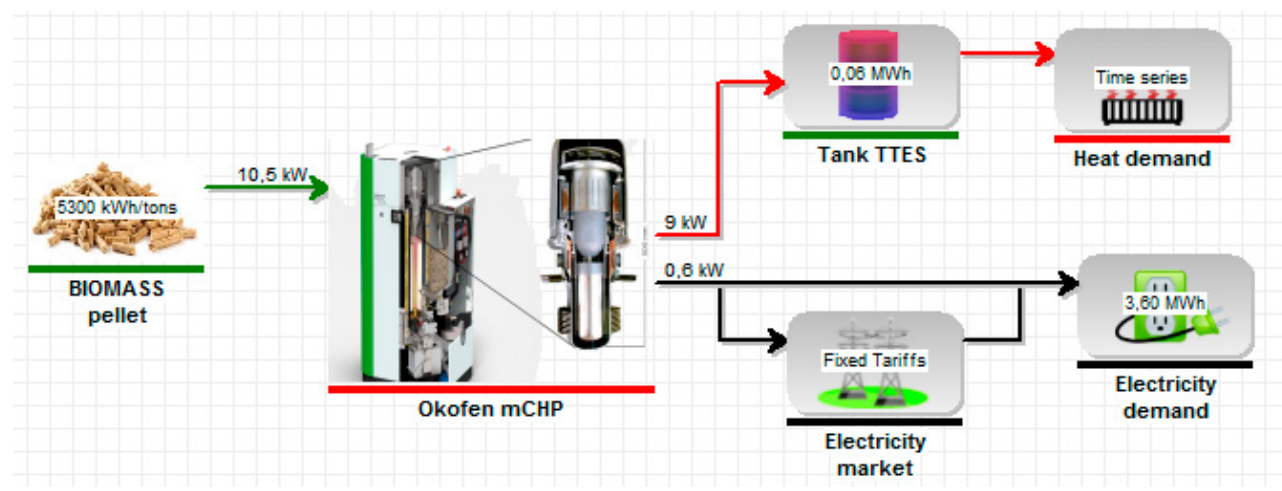

Figure 6. Scheme of the mCHP system, graphical user interface from the energyPRO 4.0 software.

\section{Modelling of a Biomass-Fired mCHP Unit for Peak Shaving}

The simple modelling of the operation of an mCHP system was carried out using the energyPRO 4.0 software. Figure 6 shows the main part of the developed model. For heat and electricity production, the biomass-fired boiler ÖkoFEN Pellematic Condens_e (ÖkoFEN, Niederkappel, Austria) with a Stirling engine was used. The boiler was supplied with wood pellets, which were burnt in the combustion chamber where the heat was produced. The exhaust fumes heated up the Stirling engine connected to the generator producing electricity. The hot water flowed from the mCHP system to a thermal energy storage (TES) tank and supplied the heating system of the building. The generated electricity satisfied the actual power demand of the building and it was possible to export the energy surplus to the national power grid via a direct connection. When the Stirling engine did not operate, the building was supplied from the power grid.

The results of the heat and power demand calculation for one year were used as the input time series to the control algorithm developed using the energyPRO software. In the standard control algorithm, the $\mathrm{mCHP}$ device operates depending on the temperature of hot water in the TES tank (i.e., on the amount of heat stored in the tank). If the temperature in the tank is too low, the mCHP device is switched on and operates until the storage is fully charged.

The standard algorithm uses the mCHP device primarily for the production of heat and its supply to the thermal energy storage tank. The amount of heat produced depends only on the storage temperature:

$$
\left(\dot{Q}_{t h}, P_{e l}\right)_{\text {prod }}=f_{\text {st }}\left(T_{\text {storage }}\right)
$$

The additionally produced electricity is used up in the house and/or exported to the power grid.

The authors developed the method and algorithm for the shaving of the peak electricity demands. In this algorithm, the mCHP unit with a Stirling engine was primarily used for electricity generation mainly during these high electricity demands. The amount of the electricity and heat produced depended on the electricity profile and heat demand profile, time of the occurrence of peak demands, and the storage temperature:

$$
\left(\dot{Q}_{t h}, P_{e l}\right)_{\text {prod }}=f_{\text {new }}\left(\dot{Q}_{\text {th,demand }}, P_{\text {el, demand }}, \tau_{\text {peak }}, T_{\text {storage }}\right)
$$

The mCHP unit was also used for heat production during peak-free periods and the produced electricity was used up in the house and/or exported to the power grid.

Description of the new algorithm:

Based on the given power demand profile the time of appearance and duration of the morning and evening power peaks were determined.

The heat demand profiles for different seasons were determined. 
Based on the given power profile and determined heat demand profile, the profile of the mCHP unit's operation was adaptively determined; this prepared profile was further used to control the operation of the mCHP unit during its exploitation.

The primary goal was peak shaving.

The secondary goal was the supply of heat to the heating system and domestic hot water.

Heat was mainly produced in combination with the electricity generation during the peak energy demands. However, the mCHP unit could produce heat for longer than during the peak energy demands in order to store the highly enough amount of heat to prevent the mCHP unit from turning on during the peak-free periods.

If the amount of heat in the thermal storage was less than $10 \%$, the $\mathrm{mCHP}$ unit had to also produce heat during peak-free periods.

The heat losses of the storage were calculated using the Fourier law with the default values of insulation conductivity and thickness using the energyPRO software $(\lambda=0.037 \mathrm{~W} / \mathrm{mK}, \delta=100 \mathrm{~mm})$.

Due to the thermal inertia of the mCHP system, a signal for the start-up of the mCHP system was sent $1 \mathrm{~h}$ before the peak energy demand occurred.

The amount of the electricity generated in the mCHP system that exceeded the electricity demand was exported to the power grid.

The buying cost of pellets and the varying price of electricity during peak and peak-free periods was taken into account.

The mCHP worked during the morning and evening peak energy demands in order to reduce power peaks (peak shaving).

This task-oriented description of the algorithm was performed by the low-level, internal optimization algorithms included in energyPRO. The option "Island Operation" was on, and covering the internal electricity demand took precedence over the optimization of the electricity production sent to the electricity market. The option "User Defined Operation Strategy" was set to the default profile for one electricity production unit. The electricity and heat demand profiles were given, as well as the size, insulation conductivity and specific heat of the thermal storage, its lower heat energy limit, and the ambient temperature. The minimum, nominal, and maximum electric and thermal power of the $\mathrm{mCHP}$ unit was also given. Based on this input data and option settings, the internal energyPRO algorithms optimized the operation profile of the electricity/heat production in the $\mathrm{mCHP}$, which was the algorithm output. Each month was optimized separately; however, the state at the month's end was the initial state for the next month.

Figure 7 shows a comparison of the profiles of energy demand, its production and heat stored for the standard control, and the new algorithm during the winter. In the standard algorithm, the mCHP device operated when the heat demand was high to fill the 3-cubic-meter storage tank up to $63 \mathrm{kWh}$. In the new algorithm, the mCHP unit operated only during morning and evening times and supplied the tank with heat up to $33 \mathrm{kWh}$ and $28 \mathrm{kWh}$, respectively. The charging time of the TES tank and its charge level were different for both analyzed algorithms. In the standard control algorithm, the tank was charged up to $100 \%$ capacity, but in the new algorithm, the charge level was $35-66 \%$ of the tank capacity.

Figure 8 shows the power production in the $\mathrm{mCHP}$ unit, the power demand, and the difference between them. When this difference is positive, it is exported to the power grid and drawn from the grid when it is negative. Looking at Figure 8, it can be seen that more power was drawn from the power grid when the standard algorithm was used.

When the mCHP unit operated using the new algorithm, it satisfied the total demand for power during the morning peak and up to $71 \%$ of the total demand during the evening peak. In the standard algorithm, the mCHP unit worked periodically and its operating time depended only on the temperature level of the hot water in the tank, irrespective of whether any peak demands occurred. As the results show, the low coverage of the electricity consumption and production is 
visible. The mCHP unit that used the standard control algorithm often worked during peak-free time, but unfortunately at the same time when the electricity drawn from the power grid was the cheapest. Analyzing both algorithms, it can be concluded that for the standard algorithm, over 2.6 times more electricity was drawn from the power grid during the peak energy demand. When the new control algorithm was applied, 3.7 times less electricity was exported to the power grid within the year. Thanks to the new algorithm, less electricity needed to be drawn from the power grid and energy needs were met to a greater extent.

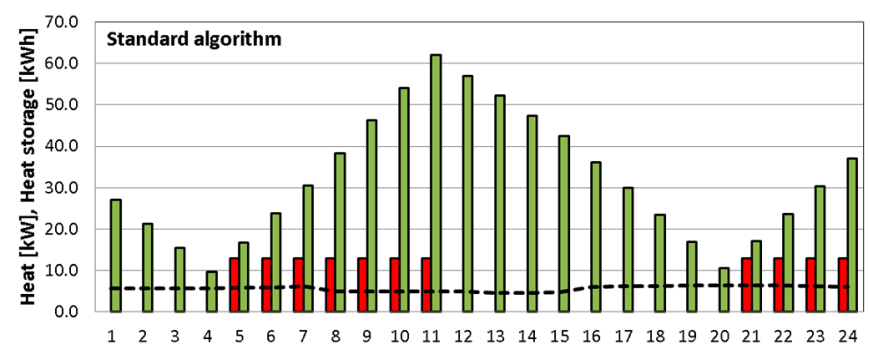

(a)

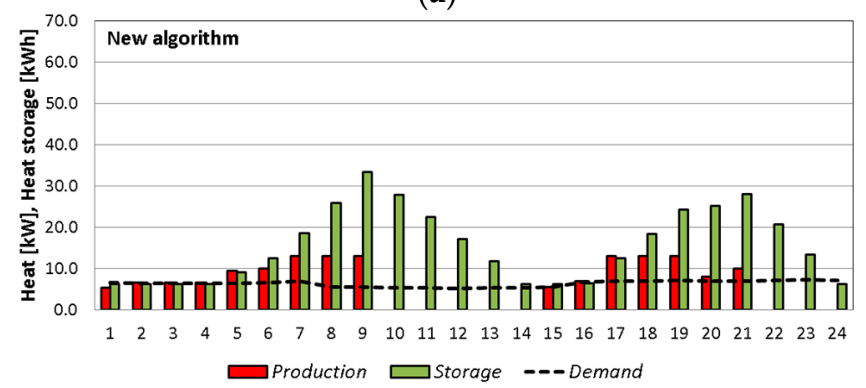

(b)

Figure 7. Profiles of the heat produced by the mCHP system $(\mathrm{kW})$ and heat stored in the tank $(\mathrm{kWh})$ with a capacity of $3 \mathrm{~m}^{3}$ during the winter season, depending on the control algorithm used: (a) standard algorithm, and (b) new algorithm.

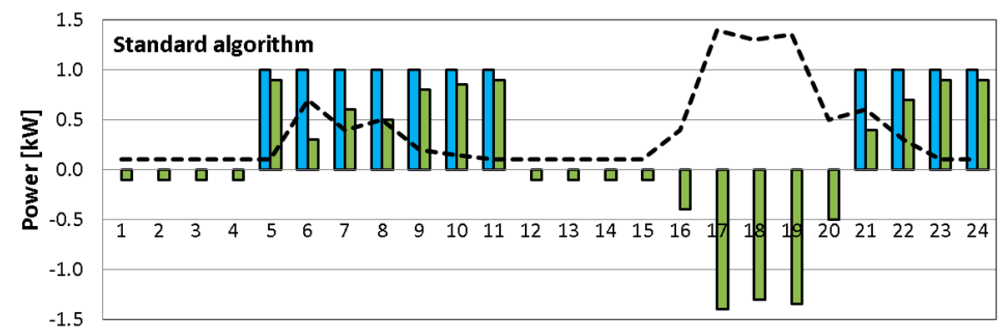

(a)

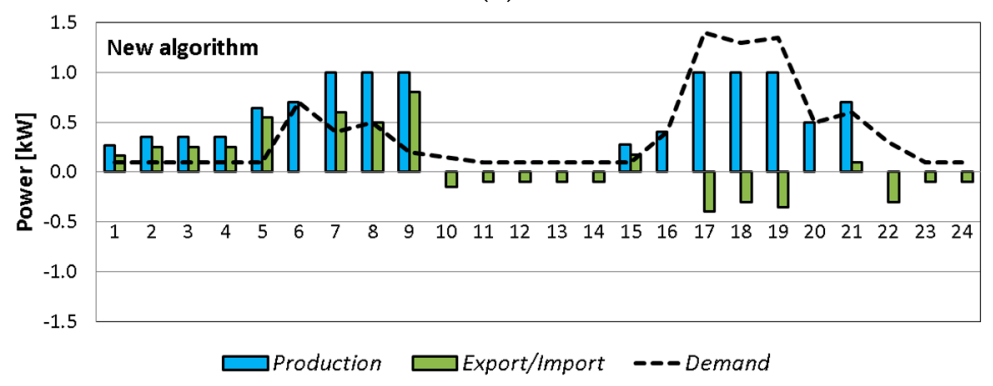

(b)

Figure 8. Profiles of the electricity demand and production in the mCHP system during winter season depending on the control algorithm used: (a) standard algorithm, and (b) new algorithm. 
Figure 9 shows the different profiles of demand for electricity and its production for all four seasons in one year using the new algorithm. Having analyzed the graphs, it can be seen that the production of electricity strongly depended on the demand for heating. In the winter the morning peak was completely covered by the electricity from $\mathrm{mCHP}$, while the evening peak was up to $71 \%$. In the spring, almost all power demand was covered by the $\mathrm{mCHP}$ production because the power demand was lower than in winter. The morning peak was completely covered and the evening one was covered up to $83 \%$. In the second transition heating periods (autumn), the morning peak was also completely covered; however, the evening one was less covered (up to $80 \%$ ) than in spring. In the summer, the power demand was the lowest; however, both the morning and evening peaks were almost not covered by the power produced in the $\mathrm{mCHP}$. This was caused by impossibility of utilization of the heat produced by the mCHP since the heat demand was the lowest in the summer.

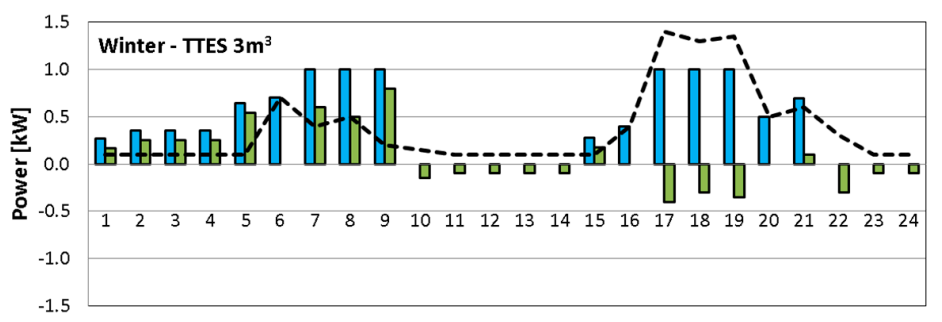

(a)

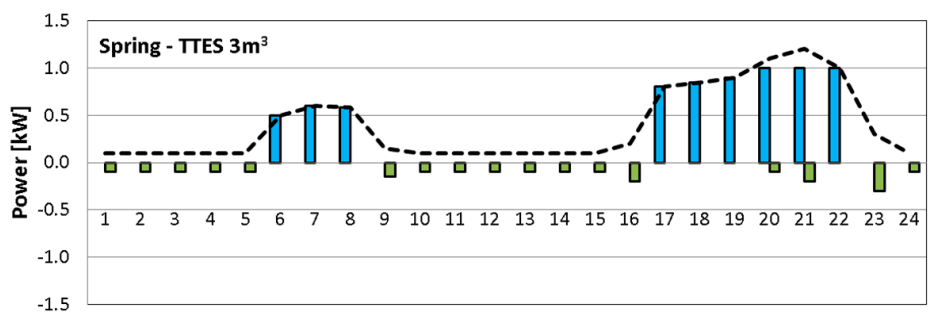

(b)

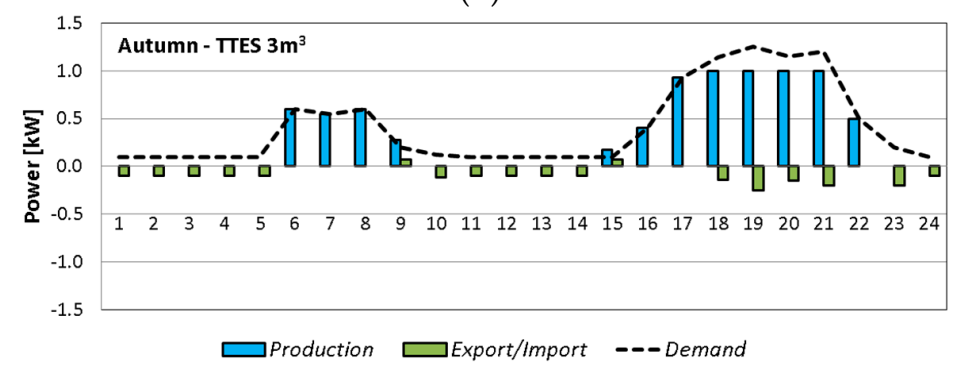

(c)

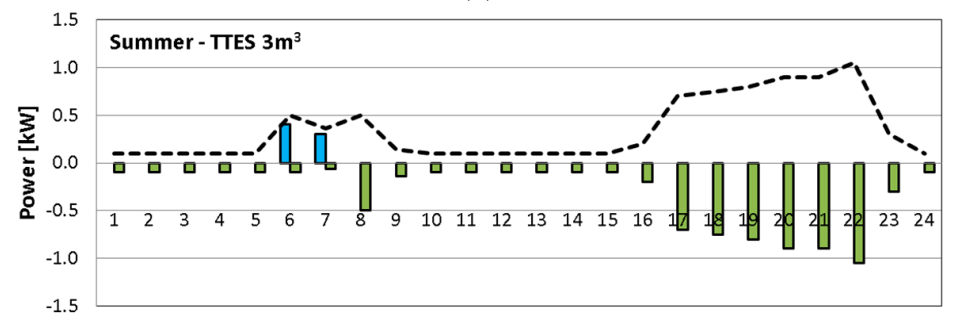

(d)

Figure 9. Comparison of the electricity demand and production in the mCHP system that used the new algorithm for each representative day of (a) winter, (b) spring, (c) autumn, and (d) summer.

Figure 10 shows a comparison of the heat demand of the building, the heat produced by the mCHP system, and the amount of heat stored in the 3-cubic-meter tank for four seasons in one year using the new algorithm. In the winter, the $\mathrm{mCHP}$ also operated before the morning peak to additionally 
produce heat due to the highest heat demand in this season. The heat was stored in the tank TES and utilized during the break between the morning and evening peaks. The mCHP was turned on before the evening peak for the same reasons as before the morning one. In the transition heating periods (spring and autumn), the mCHP operated during the morning and evening peaks only. However, the amount of heat produced during the peaks was sufficient to cover the heat demand. In the summer, the $\mathrm{mCHP}$ almost did not operate because the thermal storage reached its upper limit $(63 \mathrm{kWh})$ and was almost full all the time due to the lowest heat demand in this season. Actually, the mCHP operated $2 \mathrm{~h}$ every second day only.

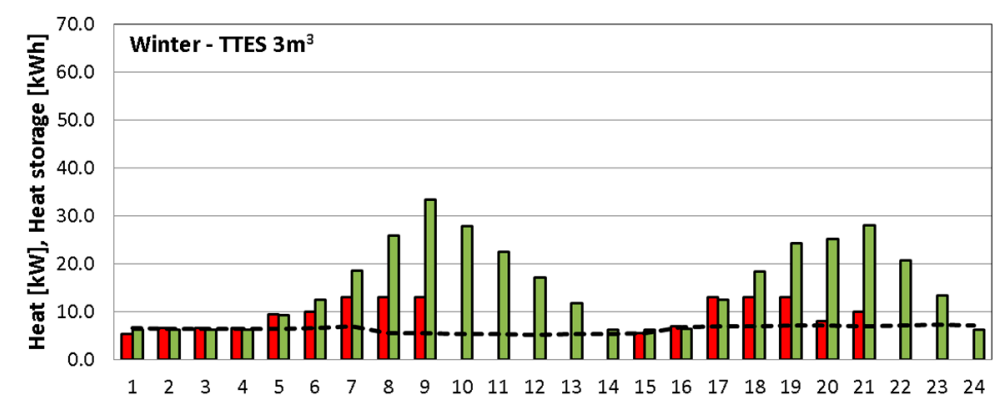

(a)

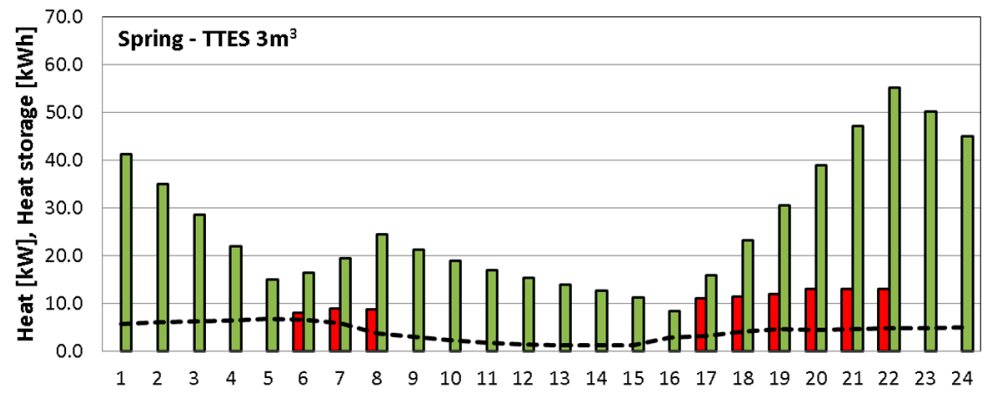

(b)

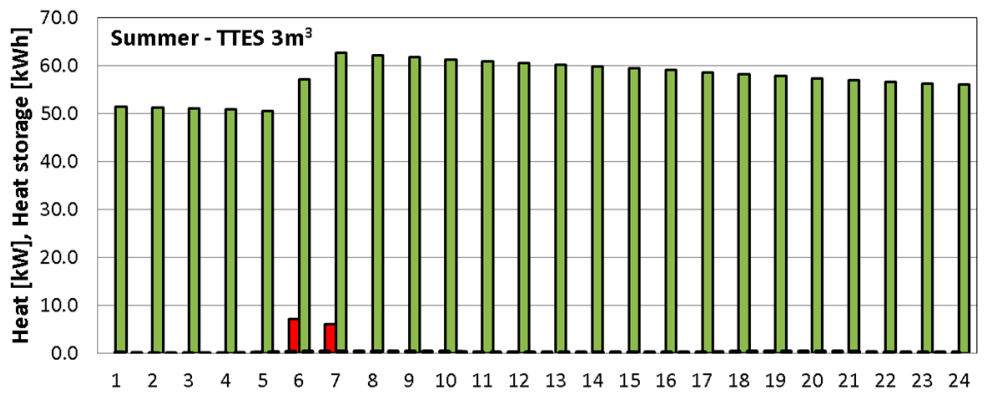

(c)

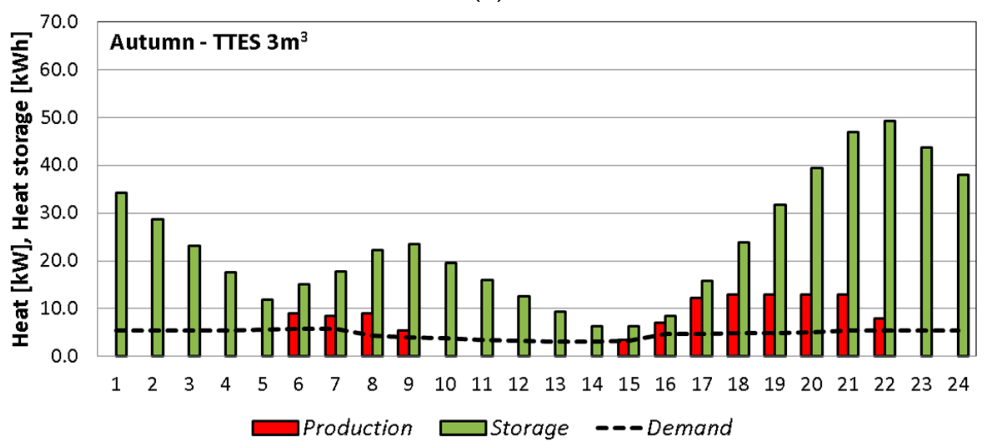

(d)

Figure 10. Comparison of the heat demand, production and storage in the mCHP system which uses the new algorithm, for each representative day of (a) winter, (b) spring, (c) summer, and (d) autumn. 
In the next step of modelling the operation of the mCHP system, the efficiency of heat and electricity production for different sizes of the TES tank were compared. In Table 1, the calculation results obtained using the energyPRO software for the operation of the $\mathrm{mCHP}$ unit within one year with three different tank sizes are presented. The total yearly efficiency is defined as the sum of heat and electricity production divided by fuel consumption within the year. The mCHP system with the largest tank (i.e., 5-cubic-meter tank) was able to produce the highest amount of electricity. The largest tank had the highest charge level as well. This also means that the largest tank had about $43 \%$ more heat loss than the 3-cubic-meter TES tank. The mCHP unit with the 3-cubic-meter tank $(63 \mathrm{kWh})$ had the highest total efficiency of cogeneration. However, this comparison of the efficiencies did not take into account the investment costs, which may be decisive when the choice of the tank is made.

Table 1. The calculation results of the mCHP unit with three different tank sizes, which operated within one year.

\begin{tabular}{ccccc}
\hline $\begin{array}{c}\text { Volume of the } \\
\left.\text { TES Tank } \mathbf{( m}^{\mathbf{3}}\right)\end{array}$ & $\begin{array}{c}\text { Total } \\
\text { Efficiency } \mathbf{( \% )}\end{array}$ & $\begin{array}{c}\text { Heat Production } \\
\mathbf{( k W h )}\end{array}$ & $\begin{array}{c}\text { Electricity } \\
\text { Production } \mathbf{( k W h )}\end{array}$ & $\begin{array}{c}\text { Fuel Consumption } \\
\mathbf{( k W h )}\end{array}$ \\
\hline 1 & 83.0 & 27,597 & 1856 & 35,492 \\
3 & 83.5 & 28,850 & 1991 & 36,929 \\
5 & 83.3 & 29,231 & 2021 & 37,507 \\
\hline
\end{tabular}

Figure 11 shows a comparison between the application of three different tank sizes. The tank with a capacity of $1 \mathrm{~m}^{3}$ was a little bit too small. During the evening peak, this tank was charged up to $100 \%$ capacity $(31 \mathrm{kWh})$, which temporarily stopped the operation of $\mathrm{mCHP}$ and disturbed the process of peak shaving at $9 \mathrm{pm}$. For the 3 and 5-cubic-meter tanks, the charging and discharging processes were very similar. However, the 5 -cubic-meter tank $(104 \mathrm{kWh})$ was too large for this application due to higher heat loss and unused capacity.

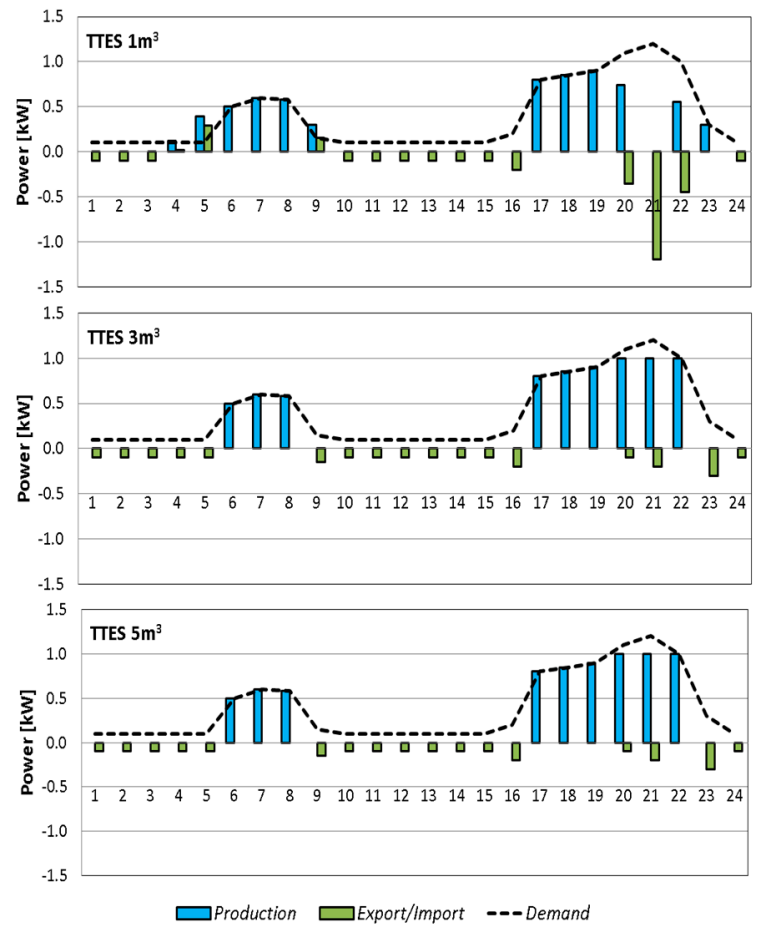

(a)

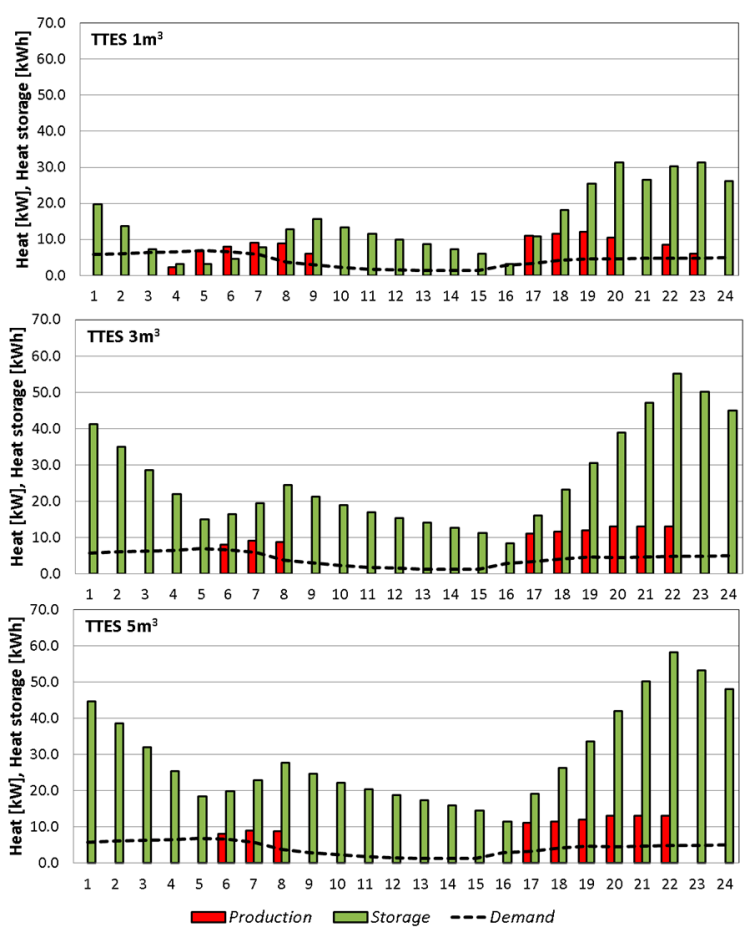

(b)

Figure 11. Comparison of the electricity demand and production (a), and heat demand, production, and storage (b) in the $\mathrm{mCHP}$ system, which used the new algorithm for three different tank sizes during the spring season. 


\section{Conclusions}

This paper discussed the modelling of an mCHP device using the energyPRO 4.0 software. The new control algorithm of the mCHP device's operation, which allows for reducing peak energy demands, was analyzed. The primary goal was peak reduction, the secondary goal was heat production out of the peaks (whereas in the standard algorithm the primary goal was heat production). This algorithm used the actual power and heat demand, as well as their daily profiles in different seasons, to control the heat and power production in the $\mathrm{mCHP}$ system. The standard control algorithm used only the temperature in the heat storage tank. Due to employing the new algorithm, the mCHP system could satisfy the total demand for energy during the morning peak and up to $71 \%$ of the total demand for energy during the evening peak. In the new algorithm, a reduced amount of energy was drawn from the power grid and the own energy demand was met to a greater extent. The effectiveness of the reduction of peak energy demands strongly depended on the demand for heating. In the transition heating periods (spring and autumn), the energy demand was satisfied to a greater extent than during the winter period. During the transition periods, the mCHP unit was able to satisfy up to $100 \%$ of the total morning peak energy demand and up to $83 \%$ of the total evening peak. In the summer, the power demand was almost completely unsatisfied by the mCHP because of the impossibility of utilization of the produced heat.

It should be noted that the size of the mCHP unit's heat storage tank affected the efficiency of the reduction of the peak energy demands. The optimal size of the heat storage tank was chosen to be $3 \mathrm{~m}^{3}$.

The very important advantage of the analyzed algorithm is the possibility of reduction of the local (within the household) peak energy demands. This individual reduction does not require the coordination between the other households in the local power grid.

Looking into these actions from a broader perspective, installing mCHP devices in many buildings in the local power grid can decrease the grid's load and provide more stable electric parameters during peak demands for energy.

Author Contributions: Conceptualization and Calculation, M.G.; Writing-Original Draft Preparation, M.G. and C.B.; Writing-Review \& Editing, W.R.; Supervision, C.B. and S.B.; Project Administration and Funding Acquisition, S.B.

Funding: This research was funded by the European Union's Horizon 2020 grant number 692197.

Acknowledgments: The collaboration between the authors was made possible and was supported by the SUPREME project. The project has received funding from the European Union's Horizon 2020 research and innovation program under Grant Agreement No. 692197.

Conflicts of Interest: The authors declare no conflict of interest.

\section{References}

1. Report of Polish Transmission System Operator (PSE) for 2017. Available online: www.pse.pl (accessed on 19 April 2018).

2. EU. Directive 2012/27/EU of the European Parliament and of the Council of 25 October 2012 on energy efficiency, amending Directives 2009/125/EC and 2010/30/EU and repealing Directives 2004/8/EC and 2006/32/EC. Off. J. Eur. Union 2012, 55, 1-97.

3. Muratori, M.; Schuelke-Leech, B.A.; Rizzoni, G. Role of residential demand response in modern electricity markets. Renew. Sustain. Energy Rev. 2014, 33, 546-553. [CrossRef]

4. Lund, H.; Andersen, A.N. Optimal designs of small CHP plants in a market with fluctuating electricity prices. Energy Convers. Manag. 2005, 46, 893-904. [CrossRef]

5. Torriti, J. Price-based demand side management: Assessing the impacts of time-of-use tariffs on residential electricity demand and peak shifting in Northern Italy. Energy 2012, 44, 576-583. [CrossRef]

6. Venizelou, V.; Philippou, N.; Hadjipanayi, M.; Makrides, G.; Efthymiou, V.; Georghiou, G.E. Development of a novel time-of-use tariff algorithm for residential prosumer price-based demand side management. Energy 2018, 142, 633-646. [CrossRef] 
7. Baeten, B.; Rogiers, F.; Helsen, L. Reduction of heat pump induced peak electricity use and required generation capacity through thermal energy storage and demand response. Appl. Energy 2017, 195, 184-195. [CrossRef]

8. Uddin, M.; Romlie, M.F.; Abdullah, M.F.; Abd Halim, S.; Abu Bakar, A.H.; Chia Kwang, T. A review on peak load shaving strategies. Renew. Sustain. Energy Rev. 2018, 82, 3323-3332. [CrossRef]

9. Rosato, A.; Sibilio, S.; Ciampi, G. Energy, environmental and economic dynamic performance assessment of different micro-cogeneration systems in a residential application. Appl. Therm. Eng. 2013, 59, 599-617. [CrossRef]

10. Sartor, K.; Quoilin, S.; Dewallef, P. Simulation and optimization of a CHP biomass plant and district heating network. Appl. Energy 2014, 130, 474-483. [CrossRef]

11. ÖkoFEN Forschungs-und Entwicklungs Ges.m.b.H.-mCHP Manufacturer's Website. Available online: http:/ / www.okofen-e.com/en/pellematic_condens_e/ (accessed on 11 June 2018).

12. Allison, J.; Cowie, A.; Galloway, S.; Hand, J.; Kelly, N.J.; Stephen, B. Simulation, implementation and monitoring of heat pump load shifting using a predictive controller. Energy Convers. Manag. 2017, 150, 890-903. [CrossRef]

13. Angrisani, G.; Canelli, M.; Roselli, C.; Sasso, M. Integration between electric vehicle charging and micro-cogeneration system. Energy Convers. Manag. 2015, 98, 115-126. [CrossRef]

14. López, M.A.; De La Torre, S.; Martín, S.; Aguado, J.A. Demand-side management in smart grid operation considering electric vehicles load shifting and vehicle-to-grid support. Int. J. Electr. Power Energy Syst. 2015, 64, 689-698. [CrossRef]

15. Maghanki, M.M.; Ghobadian, B.; Najafi, G.; Galogah, R.J. Micro combined heat and power (MCHP) technologies and applications. Renew. Sustain. Energy Rev. 2013, 28, 510-524. [CrossRef]

16. Murugan, S.; Horák, B. A review of micro combined heat and power systems for residential applications. Renew. Sustain. Energy Rev. 2016, 64, 144-162. [CrossRef]

17. Martinez, S.; Michaux, G.; Salagnac, P.; Bouvier, J.-L. Micro-combined heat and power systems (micro-CHP) based on renewable energy sources. Energy Convers. Manag. 2017, 154, 262-285. [CrossRef]

18. Rosato, A.; Sibilio, S. Performance assessment of a micro-cogeneration system under realistic operating conditions. Energy Convers. Manag. 2013, 70, 149-162. [CrossRef]

19. Comodi, G.; Cioccolanti, L.; Renzi, M. Modelling the Italian household sector at the municipal scale: Micro-CHP, renewables and energy efficiency. Energy 2014, 68, 92-103. [CrossRef]

20. Ummenhofer, C.D.; Olsen, J.; Page, J.; Roediger, T. How to improve peak time coverage through a smart-controlled MCHP unit combined with thermal and electric storage systems. Energy Build. 2017, 139, 78-90. [CrossRef]

21. Cooper, S.J.G.; Hammond, G.P.; McManus, M.C.; Rogers, J.G. Impact on energy requirements and emissions of heat pumps and micro-cogenerators participating in demand side management. Appl. Therm. Eng. 2014, 71, 872-881. [CrossRef]

22. Angrisani, G.; Canelli, M.; Roselli, C.; Sasso, M. Microcogeneration in buildings with low energy demand in load sharing application. Energy Convers. Manag. 2015, 100, 78-89. [CrossRef]

23. Parker Danny, S. Research Highlights from a Large Scale Residential Monitoring Study in a Hot Climate. In Proceedings of the International Symposium on Highly Efficient Use of Energy and Reduction of its Environmental Impact, Osaka, Japan, 22-23 January 2002; pp. 108-116.

(C) 2019 by the authors. Licensee MDPI, Basel, Switzerland. This article is an open access article distributed under the terms and conditions of the Creative Commons Attribution (CC BY) license (http://creativecommons.org/licenses/by/4.0/). 